\title{
Advanced Lung Cancer Survival in Times of Economic Hardship: A Greek Paradigm
}

\author{
Konstantinos Miltiadou ${ }^{1,2}$, Ioannis Kalantzis ${ }^{2,3}$, Maria Paraskeva ${ }^{4}$, Zisimangelos $^{2}$ \\ Solomos ${ }^{5}$, Angeliki Tsifi, Dimitrios Theodoridis ${ }^{7}$, Elena Riza ${ }^{8}$, Konstantinos \\ Triantafyllou ${ }^{1}$, Christos Kosmas ${ }^{2}$
}

${ }^{1}$ Hepatogastroenterology Unit, $2^{\text {nd }}$ Department of Internal Medicine-Propaedeutic, Research Institute and Diabetes Center, Medical School, National and Kapodistrian University, Attikon University General Hospital, Athens, Greece. ${ }^{2}$ Department of Medical Oncology, "Metaxa" Special Cancer Hospital, Piraeus, Greece. ${ }^{3}$ Gastroenterology Department, Korgialeneio - Mpenakeio Hellenic Red Cross Hospital, Athens, Greece. ${ }^{4} 2^{\text {nd }}$ Department of Respiratory Medicine, 'Sismanogleio - Amalia Fleming" Athens General Hospital, Athens, Greece. ${ }^{5}$ Doctors of the World, Athens, Greece. Postgraduate Programme "International Health - Health Crisis Management" Medical School, National and Kapodistrian University of Athens, Athens, Greece. 'Intensive Care Unit - Konstantopouleio General Hospital of Nea Ionia - Patision. Postgraduate Programme "International Health - Health Crisis Management" Medical School, National and Kapodistrian University of Athens, Athens, Greece. ${ }^{7}$ Hematology Department, Konstantopouleio General Hospital of Nea Ionia - Patision. Postgraduate Programme "International Health - Health Crisis Management" Medical School, National and Kapodistrian University of Athens, Athens, Greece. ${ }^{8}$ Department of Hygiene, Epidemiology and Medical Statistics, Medical School, National and Kapodistrian University of Athens. Postgraduate Programme "International Health - Health Crisis Management" Medical School, National and Kapodistrian University of Athens, Athens, Greece.

\begin{abstract}
Objective: Greece has been affected more than any other European country from the financial crisis that began in 2010. Just 20 months after Greece exited an eight-year long aid program, forecasts of a new recession within 2020 due to COVID-19 pandemic make concerns regarding the compromise of health care quality within the new crisis relevant once again. In this study we sought to evaluate clinical outcomes in patients with advanced lung cancer in the pre-crisis and crisis era in a dedicated oncology centre in Greece. Methods: A retrospective analysis of 522 consecutive medical records of lung cancer patients admitted in a Greek dedicated cancer hospital between the years 2008-2013 was performed. Progression Free Survival (PFS) and Overall Survival (OS) were calculated for advanced lung cancer compared over two consecutive time periods using 2010 as a cutoff point. Result: 71 and 78 patients comprised the study sample for the two periods. PFS and OS were similar over the two periods (7.73 [6.42-9.04] vs. 6.03 [5.02-7.04] and 13.70 [9.61-17.79] vs. 11.08 [7.74-15.92] months, respectively). Higher Performance Status (PS) was associated with worse survival measures over both periods, while no statistical significance was reached for OS in the latter period. Dissimilarities in PFS were observed between beneficiaries of different insurance trusts. Conclusion: Clinical outcomes for advanced lung cancer have not changed as a result of the financial crisis in our institution. The insurance provider seems to affect health outcomes. This old paradigm could serve as new guidance in the forthcoming recession due to COVID-19 pandemic.
\end{abstract}

Keywords: Financial crisis-mortality- lung cancer- health impact- Greece

Asian Pac J Cancer Care, 5 (Suppl 1), 19-25

Submission Date: 05/28/2019 Acceptance Date: 07/11/2020

\section{Introduction}

The relation between socioeconomic determinants and health has long been a scientific consideration and has been studied thoroughly especially during times of

economic hardship [1-4].

The ongoing Covid-19 pandemic led to unprecedented mitigation interventions in many countries with profound

Corresponding Author:

Dr. Zisimangelos Solomos

Department Doctors of the World, Athens, Greece. Postgraduate Programme "International Health - Health Crisis Management" Medical

School, National and Kapodistrian University of Athens, Athens, Greece.

Email: zisimosmed@gmail.com 
sequelae on their economy thus an imminent new global financial crisis will be followed by the resurgence of discussions about economic recession effects on health [5]. As Greece had been greatly exposed to the effects of the previous global financial crisis of 2008, its recent example can provide vital information regarding effective health policy making [6].

In 2010, in the face of default, Greece was forced to sign the first - of others to follow - memorandum of understanding with the European regulating mechanisms (so called Troika), in return of bailout packages and reforms, including cuts to public health expenditure $[2-4,7]$.

Although the effects of austerity measures on Greece's public health have been thoroughly analyzed by the scientific community [2-4, 7], data from other health sectors, such as cancer care, remain scarce [8-9].

"Metaxa" Cancer Hospital is located at Piraeus region in Attica, Greece. With 500 beds it is probably the largest of the four dedicated cancer hospitals in the country. It serves a population of more than 2,000,000 people, but also accepts referrals from all over Greece. Treatment and hospitalization expenses in Greece are fully covered by the patients' social health insurance provider which differs according to their profession. As far as our dedicated oncology center is concerned, numerous complaints by patients regarding the compromise of their healthcare appeared on the media, during the recent economic crisis [10]. They mostly reported delays and unavailability of treatment, shortages of medication and barriers to their access to the hospital. Malfunctioning medical equipment and hospital understaffing may have also contributed to the deterioration of the quality of the provided service [11].

Driven by these allegations, we sought to investigate if clinical outcomes had changed in our patients as a result of the crisis. Using 2010 as a cutoff point, we performed a retrospective, observational single center study to examine the health outcomes for patients with advanced wild type (wt) Non-Small Cell Lung Cancer (NSCLC) and Small Cell Lung Cancer (SCLC) over two consecutive time periods in relation to disease specific treatment.

Lung cancer is the most common cancer in the world today and a major cause of cancer mortality. Based on histopathology, lung cancer is classified in two major categories: SCLC and NSCLC. NSCLC is further comprised mainly by adenocarcinoma (AC), squamous cell carcinoma (SCC) and large cell (LC) carcinoma. Time trends regarding the histological types have been reported, probably reflecting population - level changes to smoking behavior. Although tobacco smoking is related to all histological types, it is more strongly associated to SCC, followed by SCLC and AC. The prognosis of lung cancer remains poor [12]. Molecular abnormalities in NSCLC such as activating epidermal growth factor receptor (EGFR) mutations, are found in approximately 10 to $15 \%$ of patients with lung adenocarcinoma, resulting in changes in patient management since the introduction of targeted therapies (TKI inhibitors etc.) [13]. Chemotherapy has remained the treatment of choice for advanced lung cancer patients without detectable genetic mutations [14], thus making this category of patients suitable for comparison, over two different time periods for which there were no advances or changes in treatment.

\section{Materials and Methods}

This is a retrospective, observational single center study. The research protocol was approved by the hospital's scientific, ethics and administrative committees and statements of confidentiality were signed thus conforming to all ethical issues.

All the medical records of lung cancer patients admitted in the years 2008-2013 were examined and 2010 was used as the cutoff point in order to divide the patients in the pre-crisis (2008-2010) and crisis (2010-2013) groups. For the purpose of the study, we enrolled only clinically staged IV wt NSCLC and SCLC patients according to the American Joint Committee for Cancer- International Association's for the Study of Lung Cancer (AJCC-IASLC) $7^{\text {th }}$ edition of cancer staging manual [15]. Patients had to be initially staged (not restaged) and to have been subjected to standard first line chemotherapy excluding targeted agents within 2008-2013.

The exclusion criteria comprised of inconclusive diagnosis or initial staging, unexpected (for any reason) or early discontinuation of chemotherapy resulting in unacceptable delays and incomplete regimens, missing or impossible to interpret medical record data and concurrent malignancy of such biological behavior and extend, able to affect prognosis of lung cancer or stage I-III disease.

Demographic and epidemiological data as well as survival measures, namely progress free survival (PFS) and overall survival (OS) were calculated and compared, over the two consecutive time periods. PFS was defined as time in months from first line treatment initiation to the date of radiographically or clinically observed disease progression. Similarily OS was defined as time in months from the date of diagnosis to the date of patient death.

Qualitative data - presented as absolute and value percent- were assessed by Chi-square test. Qualitative data presented either as median value (IQR) or mean value $( \pm \mathrm{SD})$ were assessed either by non-parametric tests or student's t-test, respectively. Differences in PFS and OS -presented as median value $(95 \% \mathrm{CI})$ - between the groups were compared by survival model (Kaplan-Meir, Log Rank Test). Statistical significance was set as two sided $\mathrm{p}=.05$. Statistical analyses were performed with SPSS software (IBM SPSS Statistics for Windows).

\section{Results}

Out of 522 lung cancer admissions in the observation period (2008 - 2013), only 149 patients were eligible for inclusion in our study (stage IV wt NSCLC and SCLC, receiving standard first line chemotherapy). The alleged "pre crisis" and "crisis" periods were comprised of 78 and 71 patients respectively.

The male to female ratio was 3.47 . The mean age at diagnosis was $64.27 \pm 9.60$ years. Their baseline 
Table 1. Patients' baseline Characteristics According to Enrollment Period

\begin{tabular}{|c|c|c|c|}
\hline & $<2010$ & $>2010$ & \\
\hline & $\mathrm{n}=71$ & $\mathrm{n}=78$ & $\mathrm{P}$ \\
\hline Gender, Male /Female, n & $51 / 20$ & $59 / 19$ & 0.6 \\
\hline Age at diagnosis, yrs & $61.8 \pm 10.53$ & $63.73 \pm 8.73$ & 0.22 \\
\hline \multicolumn{4}{|l|}{ Histology, n (\%) } \\
\hline SCLC & $25(35.2)$ & $17(21.8)$ & 0.07 \\
\hline NSCLC & $46(64.8)$ & $61(78.2)$ & \\
\hline \multicolumn{4}{|l|}{ Performance status, n (\%) } \\
\hline 0 & $24(54.5)$ & $32(54.2)$ & \\
\hline 1 & $14(31.8)$ & $20(33.9)$ & 0.76 \\
\hline 2 & $5(11.4)$ & $4(6.8)$ & \\
\hline 3 & $1(2.3)$ & $3(5.1)$ & \\
\hline \multicolumn{4}{|l|}{ Insurance provider, n (\%) } \\
\hline OGA & $5(7.1)$ & $6(8.1)$ & \\
\hline IKA & $45(64.3)$ & $38(51.4)$ & \\
\hline $\mathrm{ON}$ & $4(5.7)$ & $13(17.6)$ & 0.25 \\
\hline OAEE & $5(7.1)$ & $5(6.8)$ & \\
\hline Other & $11(15.7)$ & $12(16.2)$ & \\
\hline
\end{tabular}

Table 2. Progression Free Survival, Months (median [95\%CI]), According to Enrollment Period

\begin{tabular}{lcc}
\hline & $<2010$ & $>2010$ \\
\hline Overall & $7.73[6.42-9.04]$ & $6.03[5.02-7.04]$ \\
Gender & $\mathrm{P}=0.49$ & $\mathrm{P}=0.22$ \\
Male & $7.93[6.36-9.49]$ & $4.97[3.75-6.19]$ \\
Female & $7.20[9.26-10.14]$ & $9.03[5.19-12.87]$ \\
Performance status & $\mathrm{p}<0.0001$ & $\mathrm{p}<0.015$ \\
0 & $9.07[7.10-11.04]$ & $6.50[5.08-7.93]$ \\
1 & $7.33[2.01-12.65]$ & $4.30[1.52-7.08]$ \\
2 & $7.17[0.00-14.56]$ & $5.33[0.00-11.18]$ \\
3 & $2.03[2.03-2.03]$ & $2.77[1.81-3.73]$ \\
Age at diagnosis & $\mathrm{P}=0.39$ & $\mathrm{P}=0.46$ \\
$<65$ & $7.00[5.17-8.83]$ & $4.57[1.92-7.23]$ \\
$\geq 65$ & $9.07[6.43-11.71]$ & $6.23[4.36-8.10]$ \\
Histology & $\mathrm{P}=0.071$ & $\mathrm{P}=0.942$ \\
NSCLC & $8.70[7.21-10.19]$ & $5.60[3.56-7.64]$ \\
SCLC & $6.33[4.53-8.13]$ & $7.33[4.74-9.93]$ \\
Insurance provider & $\mathrm{P}=0.061$ & $\mathrm{P}=0.01$ \\
OGA & $12.13[9.64-13.62]$ & $11.07[4.91-17.23]$ \\
IKA & $7.73[6.11-9.35]$ & $6.47[4.76-8.18]$ \\
ON & $6.33[4.14-8.53]$ & $2.50[2.17-2.8]$ \\
OAEE & $8.70[7.91-9.50]$ & $4.37[0.00-8.88]$ \\
Other & $5.33[1.30-9.37]$ & $5.33[3.00-7.65]$ \\
\hline
\end{tabular}

characteristics are shown in Table 1 according to the enrollment period (2008-2010 and after 2010). While there was no difference regarding gender, age at diagnosis, PS and insurance provider distribution between the two studied periods, there were more NSCLC subjects after 2010 as compared to those with SCLC (61 or $78.2 \%$ vs. 46 or $64.8 \%$; $=0.07)$.
PFS was available for all $(n=71$ before $2010 ; n=78$ after 2010) patients. The median PFS was 7.73 [6.42-9.04] and 6.03 [5.02-7.04] months $(\mathrm{p}=0.75)$ for the two studied periods, respectively (Table 2, Figure 1A). Gender, age at diagnosis (<65 vs. $\geq 65$ years) and histology (SCLC vs. NSCLC) had no effect on PFS in both periods. On the contrary and as expected the higher the PS the shorter the 
A

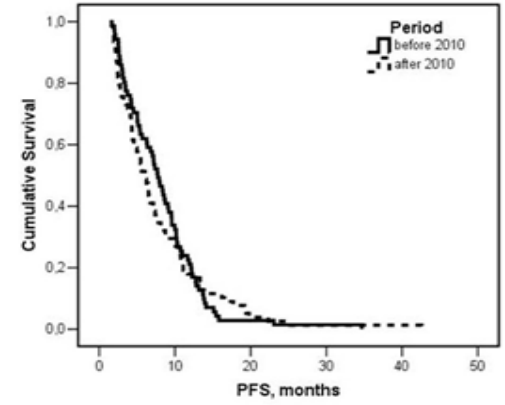

B

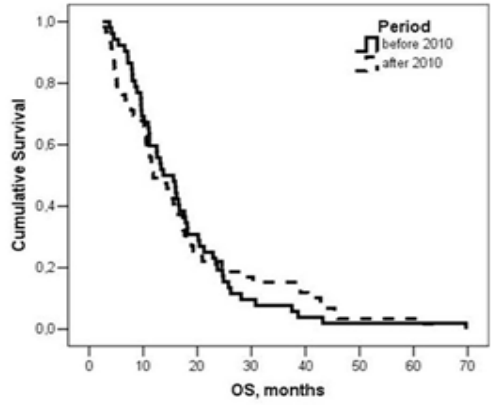

Figure 1. (A) Kaplan Meir Curve Showing Similar PFS in the Two Compared Periods (B) Kaplan Meir Curve Showing Similar OS in the Two Compared Periods

PFS in the two periods $(\mathrm{p}<0.015)$. Maritime Insurance Trust beneficiaries (MITB) had shorter $(p=0.01)$ PFS in the later observation period compared to the other trusts' beneficiaries.

OS was available for 111 ( $\mathrm{n}=52$ before $2010 ; \mathrm{n}=59$ after 2010) patients. As shown in Table 3 and in Figure 1B, there was no difference $(\mathrm{p}=0.96)$ regarding OS between the two periods (13.70 [9.61-17.79] vs. 11.08 [7.74-15.92] months, respectively). Neither gender nor age at diagnosis nor insurance provider was related to shorter OS. On the contrary, higher PS and SCLC histology were associated with shorter $\mathrm{OS}(\mathrm{p}<0.001$ and $\mathrm{p}=0.013$, respectively) only in the first period of observation.

\section{Discussion}

This study aimed to assess whether the health outcomes of advanced lung cancer patients have changed during the financial crisis era in a specialized oncology center in Greece.

The rationale supporting the choice of 2010 as the cutoff point was based on available literature and economic data. 2010 is widely assumed by researchers as the tipping point in Greece's healthcare expenditure

Table 3. Overall Survival, Months (Median [95\%CI]), According to Enrollment Period

\begin{tabular}{lcc}
\hline & $<2010$ & $>2010$ \\
\hline Overall & $13.70[9.61-17.79]$ & $11.08[7.74-15.92]$ \\
Gender & $\mathrm{P}=0.91$ & $\mathrm{P}=0.72$ \\
Male & $15.60[9.72-21.48]$ & $11.50[10.14-12.87]$ \\
Female & $13.70[9.09-18.31]$ & $15.57[11.45-19.69]$ \\
Performance status & $\mathrm{p}<0.01$ & $\mathrm{p}<0.182$ \\
0 & $21.23[5.00-37.46]$ & $15.00[5.00-25.00]$ \\
1 & $13.13[5.93-20.33]$ & $10.50[9.60-11.40]$ \\
2 & $9.73[9.52-9.95]$ & $6.80[0.00-16.28]$ \\
3 & $5.40[5.40-5.40]$ & $4.10[2.50-5.70]$ \\
Age at diagnosis & $\mathrm{P}=0.72$ & $\mathrm{P}=0.47$ \\
$<65$ & $12.50[6.34-18.66]$ & $11.67[6.26-17.08]$ \\
$\geq 65$ & $16.20[10.88-21.52]$ & $12.80[6.11-19.49]$ \\
Histology & $\mathrm{P}=0.013$ & $\mathrm{P}=0.973$ \\
NSCLC & $15.93[10.25-21.61]$ & $11.50[6.70-16.30]$ \\
SCLC & $9.73[7.50-11.97]$ & $12.80[6.74-18.86]$ \\
Insurance provider & $\mathrm{P}=0.311$ & $\mathrm{P}=0.174$ \\
OGA & $15.60[2.60-28.61]$ & $43.67[6.38-80.96]$ \\
IKA & $13.27[7.71-18.83]$ & $12.80[6.36-19.24]$ \\
ON & $8.00[8.00-8.00]$ & $5.030[3.77-6.29]$ \\
OAEE & $21.23[21.23-21.23]$ & $8.20[0.00-18.88]$ \\
Other & $16.20[5.39-27.01]$ & $9.67[1.28-18.06]$ \\
\hline
\end{tabular}


[16-18]. This assumption is based on the fact that the consequences of the financial crisis had not been largely perceivable until late 2010, when Greece signed the first Memorandum of Understanding and measures of reduction of health spending began to be implemented [19]. Between 2009 and 2014, expenditure on healthcare decreased by more than $25 \%$, average wages decreased by $20 \%$ and unemployment increased from $9.6 \%$ to $26.5 \%$ [8], while Greece witnessed a $29 \%$ drop in its gross domestic product (GDP) \{Karanikolos, 2016 \#2439\}. Health care spending was drastically reduced from its peak $9.56 \%$ of the GDP in 2010 , to $7.95 \%$ by 2014 [20] or from $9.85 \%$ to $8.29 \%$ according to the national statistical authority [21]. In a similar way, the $2^{\text {nd }}$ health region of Greece, where the reference hospital is located, underwent substantial budget cuts after 2010 and until the end of the crisis, which affected our institution as well [22].

The fact that no differences in survival measures namely OS and PFS - were noted in our institution between the two time periods, despite the presumed effects of the recession, is a matter of debate. Previous local research in the field yielded similar results with the researchers finding no significant changes on the PFS and OS of lung cancer patients before or after the financial crisis, setting 2008 as a benchmark year [9-23]. One might argue that this is to be expected, as no significant changes have been noted in the management of these patients between the two time periods in relation to disease specific therapy [14]. As for availability of treatment is concerned, national statistics show significant cuts in pharmaceutical spending during the crisis [20]. However, a recent study from Greece regarding advanced lung cancer targeted treatment in the crisis era, showed that despite restrictions in the reimbursement policy patients still gained access to treatment through parallel national programs, while any temporary unavailability of treatment was not substantial enough to affect the anywise dreadful prognosis of the disease [8].

It can also be speculated that tertiary care has not been compromised by the crisis in contrary to primary care [19]. Therefore, the fact that no differences on survival were noted for the specific disease and time frame, does not exclude that the crisis might not have impacted on other aspects of public health, nor that the quality of care has not been compromised. Further research is warranted to address these questions.

The potential effect of the patients' health insurance provider on prognosis is of great interest. According to Greece's social insurance model, at the time the study was conducted, every employee was obligatory insured to a specific provider (e.g. maritime workers to Maritime Insurance Trust $(\mathrm{ON})$, farmers to Agricultural Insurance Trust (OGA), freelancers to Social Insurance Trust (IKA), medical and health workers to Health Workers Insurance Trust (TSAY) etc. It has been argued that patients received different benefits according to their provider (e.g. some providers like IKA or National Bank Insurance Trust (TYPET) had their own hospitals thus allowing better access to health services). In addition, professional exposure to harmful substances, education, nutrition or other imponderable factors could be masked behind the provider (ON, OGA, and TSAY). Unfortunately, this information is hindered due to the unavailability of detailed and easily accessible medical records. This is a matter that needs to be addressed in the future.

Performance status was found to affect prognosis. The highest the PS the worse the PFS and OS. This is an expectable finding, as it makes sense for a patient presenting at a poorer clinical condition to have a worst prognosis. It is well known that these patients cannot tolerate chemotherapy, have more disease or treatment related complications, longer hospital stays and overall higher mortality and morbidity rates [24].

As far as the advantages of this study are concerned, caution was undertaken to avoid all possible confounding factors that could cause misinterpretation of the results, by strict adherence to the research protocol. The population of the first observation period had similar baseline characteristics with the population of the second observation period, except for more NSCLC cases enrolled after 2010 (Table 1). Disease specific therapy and demographics were also the same, thus allowing the assumption that the population comprising the two groups is practically identical and suitable for comparison.

Nevertheless, the study carries several limitations, although efforts were made to address most of them: Firstly, this is a retrospective single-center study thus inferences about nationwide advanced lung cancer survival in Greece in the time of crisis cannot be drawn with certainty from current data, while the study's limited sample size may not address all variables in a decisive manner. The population of the study also might not be representative of the general Greek stage IV lung cancer population, although Metaxa Hospital is probably the largest cancer hospital in Greece and accepts referrals from all over the country. In addition, due to the study's retrospective character and cross-sectional insight into the problem any correlation of the financial crisis to the patients' health outcomes should be made with caution as confounding factors, that could not be controlled or predicted, may have penetrated. One might also argue that the selection of a cutoff point other than 2010 may have changed the results the study, however, as already explained, the consideration of 2010 as the limit between the pre- and the crisis era has been widely adopted by researchers [16-18]. Finally, OS and PFS may be suboptimal indicators of financial crisis influence on cancer patients' health, although they have been similarly used in literature [23].

In conclusion, in our institution OS and PFS of stage IV wt NSCLC and SCLC patients did not differ significantly between the pre-crisis and the financial crisis era, using 2010 as a cutoff point. The insurance provider however seems to affect health outcomes in our institution, with MITB beneficiaries having shorter PFS in the second observation period compared to other trusts. This fact may imply inequities between beneficiaries according to their provider, which in turn compromised the quality of received care, thus warrants prospective research. Our findings are especially relevant nowadays, as the upcoming 
forecasted recession due to COVID-19 pandemic is once again expected to affect Greece more than any other economy in the Eurozone. This old paradigm could serve as a guide to policy makers as to the proper allocation of health resources and mitigation strategies. It seems that tertiary care is not that affected by recessions and resources probably need to be allocated to primary healthcare and equity amongst healthcare beneficiaries.

\section{Acknowledgements}

The authors contributed as follows

$$
\begin{aligned}
& \text { Study Design } \\
& \text { K.M, C.K, E.R. }
\end{aligned}
$$

\section{Data Collection}

K.M, I.K, M.P, D.T, Z.S, A.T.

$$
\begin{aligned}
& \text { Data Analysis } \\
& \text { K.T }
\end{aligned}
$$

\section{Manuscript drafing} K.M, K.T

\section{Critical revision of important intellectual content} K.T, C.K, E.R

\section{Manuscript approval} All.

\section{Funding Statement}

The authors received no specific funding for this work.

\section{References}

1. Falagas ME, Vouloumanou EK, Mavros MN, Karageorgopoulos DE. Economic crises and mortality: a review of the literature. International Journal of Clinical Practice. 2009 08;63(8):1128-1135. https://doi.org/10.1111/j.17421241.2009.02124.x

2. Kondilis E, Giannakopoulos S, Gavana M, Ierodiakonou I, Waitzkin H, Benos A. Economic Crisis, Restrictive Policies, and the Population's Health and Health Care: The Greek Case. American Journal of Public Health. 2013 06;103(6):973-979. https://doi.org/10.2105/ajph.2012.301126

3. Levy BS, Sidel V. The Economic Crisis and Public Health. Social Medicine. 2009;4(2):82-7.

4. Stuckler D, Basu S, Suhrcke M, Coutts A, McKee M. The public health effect of economic crises and alternative policy responses in Europe: an empirical analysis. The Lancet. 2009 07;374(9686):315-323. https://doi.org/10.1016/s01406736(09)61124-7

5. Ferguson N, Laydon D, Nedjati Gilani G, Imai N, Ainslie K, Baguelin M, Bhatia S, Boonyasiri A, Cucunuba Perez Z, Cuomo-Dannenburg G, Dighe A, Dorigatti I, Fu H, Gaythorpe K, Green W, Hamlet A, Hinsley W, Okell L, Van Elsland S, Thompson H, Verity R, Volz E, Wang H, Wang Y, Walker P, Winskill P, Whittaker C, Donnelly C, Riley S, Ghani A. Report 9: Impact of non-pharmaceutical interventions (NPIs) to reduce COVID19 mortality and healthcare demand. Imperial College London; 202003. https://doi.org/10.25561/77482

6. Karanikolos M, Kentikelenis A. Health inequalities after austerity in Greece. International Journal for Equity in Health. 201605 31;15(1). https://doi.org/10.1186/s12939016-0374-0

7. Karanikolos M, Mladovsky P, Cylus J, Thomson S, Basu S, Stuckler D, Mackenbach JP, McKee M. Financial crisis, austerity, and health in Europe. The Lancet. 2013 04;381(9874):1323-1331. https://doi.org/10.1016/s01406736(13)60102-6

8. Stuckler D, McKee M. There is an alternative: public health professionals must not remain silent at a time of financial crisis. The European Journal of Public Health. 201201 24;22(1):2-3. https://doi.org/10.1093/eurpub/ckr189

9. Fountzilas E, Levva S, Mountzios G, Polychronidou G, Maniadakis N, Kotoula V, Fountzilas G. Treating EGFRMutated Oncogene-Addicted Advanced Non-Small-Cell Lung Cancer in the Era of Economic Crisis in Greece: Challenges and Opportunities. Journal of Global Oncology. 2018 Dec;(4):1-12. https://doi.org/10.1200/jgo.18.00115

10. Vrachnis N, Vlachadis N, Salakos N, Vlachadi M, Iliodromiti $\mathrm{Z}$. Cancer mortality in Greece during the financial crisis. Acta Oncologica. 201409 19;54(2):287-288. https://doi.or g/10.3109/0284186x.2014.958785

11. Nedos V. Coverage of medication shortages in Metaxa cancer hospital, Kathimerini. Retrieved April 13, 2020, from https:// www.kathimerini.gr/367273/article/epikairothta/ellada/ kalyptetai-h-elleiyh-farmakoy-sto-meta3a. 2009;.

12. Androulaki E. National Healthcare System: The heavy sufferer and the broken medical equipment. CNN.gr. https:// www.cnn.gr/news/ellada/story/49905/esy-o-megalosasthenis-kai-ta-xalasmena-iatrika-mixanimata. 2016;.

13. Travis, W. (n.d.). Pathology and Genetics of Tumours of the Lung, Pleura,Thymus and Heart. Retrieved May 12, 2016, from http://www.iarc.fr/en/publications/pdfs-online/ pat-gen/bb10/..

14. Felip E, Gridelli C, Baas P, Rosell R, Stahel R. Metastatic non-small-cell lung cancer: consensus on pathology and molecular tests, first-line, second-line, and third-line therapy. Annals of Oncology. 2011 07;22(7):1507-1519. https://doi. org/10.1093/annonc/mdr150

15. Planchard D, Popat S, Kerr K, Novello S, Smit E, FaivreFinn C, Mok T, Reck M, Van Schil P, Hellmann M, Peters S. Metastatic non-small cell lung cancer: ESMO Clinical Practice Guidelines for diagnosis, treatment and follow-up. Annals of Oncology. 2018 Oct;29:iv192-iv237. https://doi. org/10.1093/annonc/mdy275

16. Edge SB, Compton CC. The American Joint Committee on Cancer: the 7th Edition of the AJCC Cancer Staging Manual and the Future of TNM. Annals of Surgical Oncology. 2010 02 24;17(6):1471-1474. https://doi.org/10.1245/s10434010-0985-4

17. Filippidis FT, Gerovasili V, Millett C, Tountas Y. Mediumterm impact of the economic crisis on mortality, healthrelated behaviours and access to healthcare in Greece. Scientific Reports. 201704 10;7(1). https://doi.org/10.1038/ srep46423

18. Katsimi M, Moutos T. EMU and the Greek crisis: The political-economy perspective. European Journal of Political Economy. 2010 Dec;26(4):568-576. https://doi. org/10.1016/j.ejpoleco.2010.08.002

19. Kentikelenis A, Karanikolos M, Reeves A, McKee M, Stuckler D. Greece's health crisis: from austerity to denialism. The Lancet. 2014 02;383(9918):748-753. https:// doi.org/10.1016/s0140-6736(13)62291-6

20. Economou C, Kaitelidou D, Kentikelenis A, Maresso A, 
Sissouras A. The impact of the crisis on the health system and health in Greece. In Economic crisis, health systems and health in Europe: Country experience [Internet]. European Observatory on Health Systems and Policies. https://www. ncbi.nlm.nih.gov/books/NBK447857/. 2015;

21. Health resources-Health spending-OECD Data. (2019). The OECD. Retrieved November 3, 2019, from http://data. oecd.org/healthres/health-spending.htm.

22. National Statistical Authority-ELSTAT. (2020). Retrieved April 14, 2020, from https://www.statistics.gr/el/statistics/-/ publication/SHE35/..

23. The transparency program initiative-Diavgeia (2020). Retrieved April 14, 2020, from https://diavgeia.gov.gr/se arch?query $=\mathrm{q}: \% 22 \% \mathrm{CF} \% 80 \% \mathrm{CF} \% 81 \% \mathrm{CE} \% \mathrm{BF} \% \mathrm{CF} \% 8$ $5 \% \mathrm{CF} \% 80$.

24. Saloustros E, Vichas G, Margiolaki A, Koumiotaki S, Androulakis N, Georgoulias V. Lung cancer in the era of Greek economic crisis. Lung Cancer. 2014 Oct;86(1):112113. https://doi.org/10.1016/j.lungcan.2014.07.016

25. Casciato, D. A. (Ed.). (2012). Manual of Clinical Oncology (Seventh edition). LWW.

\section{(c) (i) (8)}

This work is licensed under a Creative Commons AttributionNon Commercial 4.0 International License. 